\title{
PÓS-DEMOCRACIA E EDUCAÇÃO
}

POSTDEMOCRACIA Y EDUCACIÓN

\author{
CLERISTON PETRY ${ }^{1}$ ORCID: http://orcid.org/0000-0001-8900-6633
}

\begin{abstract}
RESUMO:
Apresento no artigo um estudo sobre as possibilidades educacionais num contexto "pós-democrático". A "Pós-Democracia" repercute no Brasil pela ausência de limites aos poderes (econômico, político) que flexibiliza, mercantiliza e destrói direitos, no qual a violência perverte o espaço público invisibilizando e desumanizando os indesejáveis ao projeto neoliberal. Uma pesquisa em educação não pode negligenciar a relevância de investigar sobre o contexto em que ela acontece, ao mesmo tempo em que propõe alternativas que garantam sua especificidade. Nesse sentido, a partir da interpretação de autores fundamentais, estabeleci relações com base na plausibilidade e coerência dos argumentos em auxiliar-me na construção de respostas ao problema central. A educação, para fazer frente à "Pós-Democracia", acontece privilegiadamente na escola, na qual os estudantes devem ter acesso à verdade e ao conhecimento (em contraposição à "Pós-verdade"), ao respeito aos limites (a verdade, o conhecimento, o mundo e os outros são limites ao narcisismo infantil e às perversões), à imposição de limites (a escola se torna um limite às injunções da família, da economia, da sociedade e da política), à introdução no "mundo" e ao aprendizado de valores democráticos.
\end{abstract}

Palavras-chave: Pós-Democracia, educação, limites

\section{RESÚMEN:}

Presento en el artículo un estudio sobre posibilidades educativas en un contexto "posdemocrático". La "postdemocracia" tiene repercusiones en Brasil debido a la ausencia de límites a los poderes (económicos, políticos) que relajan, mercantilizan y destruyen los derechos, en los cuales la violencia pervierte el espacio público al hacer invisibles y deshumanizar a aquellos indeseables para el proyecto neoliberal. La investigación en educación no puede descuidar la relevancia de investigar el contexto en el que tiene lugar, al proponer alternativas que garanticen su especificidad. En este sentido, basado en la interpretación de autores fundamentales, establecí relaciones basadas en la plausibilidad y coherencia de los argumentos para ayudarme en la construcción de respuestas al problema central. La educación, para enfrentar la "Postdemocracia", se realiza de forma privada en la escuela, en la que los estudiantes deben tener acceso a la verdad y al conocimiento (en oposición a la "Post-verdad"), con respecto a los límites (la verdad, el conocimiento, el mundo y otros son límites para el narcisismo y las perversiones infantiles) la imposición de límites (la escuela se convierte en un límite para los mandatos de la familia, la economía, la sociedad y la política), la introducción al "mundo" y aprender valores democráticos.

Palabras clave: Postdemocracia, educación, límites

Submetido: $10 / 09 / 2020$

Aprovado: $21 / 12 / 2020$

\footnotetext{
${ }^{1}$ Universidade Federal de Mato Grosso. Cuiabá, MT, Brasil. <cleripetry@hotmail.com>

Educação em Revista|Belo Horizonte|v.37|e25258|2021
} 


\section{INTRODUÇÃO}

Porque sim. Porque é o que estamos fazendo. Porque é nisso que acreditamos. Porque foi o que dissemos que iríamos fazer. Porque foi isso que o povo disse que queria. Porque eu vim para salvar a todos. Porque sim. Esta, em última análise, era a única resposta: porque sim (MCEWAN, 2020, p.84).

São os momentos de "crise" que exigem da Ciência, da Academia e dos políticos respostas contundentes, não fundadas em preconceitos e/ou pré-juízos, mas em reflexões e ponderações acerca dos fatos. Verdade, conhecimento e pensamento são mobilizados para apresentar uma resposta à crise, especialmente porque ela "dilacera fachadas e oblitera preconceitos", permitindo explorar a essência de tudo aquilo que foi "posto a nu" (ARENDT, 2007, p. 223) que a crise em que vivemos nos exige pensar sobre o que é a política, a democracia e qual o sentido da educação num mundo condenado à ruína.

A democracia não é, simplesmente, "poder do povo" ou "soberania do povo". Talvez seja preciso romper com essas definições simplistas e que encobrem armadilhas antidemocráticas. Primeiro, é preciso esclarecer o sentido de "povo" e, em segundo lugar, compreender que a ideia de soberania é antipolítica e, assim, antidemocrática, mesmo que seja a soberania do "povo". Seguindo uma definição "tradicional" de democracia, ela significa uma "forma de governo em que os interesses do conjunto do povo são atendidos publicamente, formando parte o mesmo povo no processo de decisão" (MONEDERO, 2012, p.74). Como "forma de governo", a democracia não diz respeito às práticas e ações dos cidadãos, mas às instituições e as garantias de funcionamento destas. Dizer que vivemos numa democracia porque as "instituições estão funcionando" ${ }^{2}$ é uma meia verdade. As "instituições democráticas", unidas pelo conceito de Estado, vem atendendo a interesses privados e à "racionalidade neoliberal", a qual neutraliza o político e, por conseguinte, a democracia. A "neutralização do político" se refere à "colonização do conflito inerente ao político pela suposta neutralidade da tecnologia, com o conseguinte deslocamento da luta em direção à arena do econômico, definida como competição" (MONEDERO, 2012, p. 77) ${ }^{3}$.

Pesquisar e escrever sobre educação exige a compreensão dos acontecimentos e dos fenômenos, porque sem a compreensão do "mundo" que nos coube viver não se pode enfrentar os problemas educacionais (TAPIAS, 1996, p. 19). Isso não quer dizer que a educação resolverá os problemas do mundo ou construirá uma sociedade melhor. Não é tarefa da educação mudar o mundo, mas dos adultos que estão aptos e, em princípio, educados. Por isso, "qualquer pessoa que se recuse a assumir a responsabilidade coletiva pelo mundo não deveria ter crianças, e é preciso proibi-la de tomar parte em sua educação" (ARENDT, 2007, p. 239). A educação não pode ser política, no sentido de ser um instrumento para a política, mas deve ser política pela tarefa que lhe cabe de introduzir os novos no "mundo" e, assim, possibilitar sua continuidade. É por isso que precisamos investigar qual o sentido da educação no contexto da pós-democracia, se a defesa de uma educação não instrumental, da escola com uma especificidade que a localiza "dentro dos muros" - fora das turbulências de nossos tempos -, é suficiente para não formar indivíduos adaptados à pós-democracia e se é possível resistir, educacionalmente, à "sociedade sem lei".

\footnotetext{
${ }^{2}$ Desde a destituição da Presidenta Dilma Rousseff, membros dos três poderes da República têm afirmado que as instituições democráticas funcionam no Brasil. Em 2016, ápice político da operação "Lava Jato”, o então juiz Sérgio Moro utilizava o jargão (http://www1.folha.uol.com.br/poder/2016/04/1759192-nao-acerto-todas-na-lava-jato-diz-juiz-sergio-moro.shtml). Por ocasião dos 30 anos da Constituição de 1988, a então presidenta do Supremo Tribunal Federal, Ministra Carmen Lúcia, disse que instituições democráticas funcionam no Brasil (https://g1.globo.com/politica/noticia/2018/08/23/carmen-luciadiz-que-instituicoes-democraticas-funcionam-no-brasil-mas-com-deficiencias.ghtml). Em 2019, o ex-Presidente Fernando Henrique Cardoso criticou o governo Bolsonaro, mas ressaltou que as instituições estão funcionando (https://oglobo.globo.com/busca/click?q=institui $\% \mathrm{C} 3 \% \mathrm{~A} 7 \% \mathrm{C} 3 \% \mathrm{~B} 5 \mathrm{es}+$ democr $\% \mathrm{C} 3 \% \mathrm{~A} 1$ ticas + est $\% \mathrm{C} 3 \% \mathrm{~A} 3 \mathrm{o}+$ funcionan do\&p $=4 \& \mathrm{r}=1585612595089 \& \mathrm{u}=\mathrm{https} \% 3 \mathrm{~A} \% 2 \mathrm{~F} \% 2 \mathrm{Fblogs}$. oglobo.globo.com $\% 2$ Fbernardo-mello-

franco $\% 2$ Fpost $\% 2$ Ffernando-henrique-brasil-esta-vivendo-sob-o-signo-do-

odio.html\&t $=$ informacional $\& \mathrm{~d}=$ false $\& \mathrm{f}=$ false\&ss $=\& \mathrm{o}=\& \mathrm{cat}=\& \mathrm{key}=5 \mathrm{aec} 2 \mathrm{f} 71 \mathrm{~d} 57317242603 \mathrm{dce} 3 \mathrm{~b} 93 \mathrm{ff} 8 \mathrm{e} 1)$.

3 Todas as traduções são de minha autoria.
} 
As "comparações" e distinções entre Bolsonaro e Hitler (apresentadas com o intuito exclusivo de esclarecer argumentos e fornecer exemplos), líderes que chegaram ao poder com apoio popular e empresarial, se limitam ao período anterior à posse nos respectivos cargos (Presidente da República e Chanceler do Reich). Não pretendo comparar biografias, porque o êxito de ambos os políticos não aconteceu exclusivamente por fatores relacionados à persona, mas ao contexto, às ideias disseminadas entre as pessoas, ao papel da ideologia e a representação, como tipificação, dessas personagens para o estudo acerca da ausência de limites aos poderes, isto é, como algumas de suas práticas revelaram tendências, especialmente, da "perda do mundo". Utilizo o recurso a alguns "personagens" almejando evidenciar que são os homens e as mulheres que contribuem com seus atos, palavras e feitos para a "história" e que esta não se constitui numa narrativa despersonalizada, como se existisse independentemente dos atores. São indivíduos com suas "vidas", interesses, desejos, visões de mundo e ideologias que nos ajudam a compreender o que aconteceu e do que nós, seres humanos, somos capazes.

É possível dizer que vivemos "tempos sombrios" quando o domínio público obscurece "e o mundo se tornou tão incerto que as pessoas deixaram de pedir à política mais do que a devida consideração pelos seus interesses vitais e pela sua liberdade pessoal" (ARENDT, 1991, p. 21). Quando isso acontece, o mundo pode ser destruído e sua ausência é uma forma de barbárie (ARENDT, 1991, p. 23). Se em "tempos sombrios" é possível esperar uma luz vinda de alguns homens e mulheres que se tornam exemplos (ARENDT, 1991, p. 10), talvez Bolsonaro e Hitler sejam a escuridão que contribui para os "tempos sombrios".

\section{O CONTEXTO “PÓS-DEMOCRÁTICO” NO BRASIL}

Eu sou a Constituição (BOLSONARO, 2020) ${ }^{4}$.

A política é o espaço da relação entre indivíduos iguais e livres na condição de cidadãos e, ainda, locus dos conflitos e não dos consensos, isto é, os consensos não podem ser o fim da democracia, na medida em que anulariam os debates e as discussões, a ação política, em favor de meios mais eficazes de consenso. A democracia é o espaço do conflito, não como fim nem como meio. A democracia é conflito e consenso e a política é o espaço mundano em que os homens se reúnem na modalidade do discurso e da ação (ARENDT, 2005). Sem a ação, portanto, sem a possibilidade do dissenso, dado que somos seres singulares, não há política e, deste modo, democracia. Mas pode haver a "democracia institucional" ou, como prefiro, a "pós-democracia", que é, também, a "pós-política". Não é "autoritarismo", na medida em que continua a se intitular como "democracia", apesar das perdas democráticas, e porque há uma tendência à ausência de limites, próxima àquela totalitária, com personagens comparáveis e dissolução das distinções básicas (público/privado, política/economia) que se iniciaram com a Modernidade mas que agora apresentam novos desdobramentos. Tais elementos possibilitam afirmar que, ontologicamente, um "pós" não necessita de um "antes", embora seja necessário logicamente. É "pós-democracia” porque ainda precisamos de uma palavra para dar conta de um fenômeno novo ${ }^{5}$, apesar de que constituído de elementos pertencentes ao próprio Ocidente.

Para Hannah Arendt (2005, p. 205), filósofa alemã, "a pluralidade humana, básica condição tanto do discurso quanto da ação, tem o duplo significado de igualdade e distinção", ou seja, se os homens não fossem iguais, não poderiam entender-se, e se não fossem distintos, não necessitariam do discurso e da ação. A política, que acontece no espaço público, só é possível quando a igualdade e a distinção são possíveis, ou seja, quando os homens atuam em conjunto num espaço de igualdade e liberdade. A

\footnotetext{
4“Eu sou a Constituição’ diz Bolsonaro, um dia após ato pró-Ditadura” (https://cbn.globoradio.globo.com/media/audio/298783/eu-sou-constituicao-diz-bolsonaro-um-dia-apos-ato-.htm). 5 “<< post $>>$ [...] é indicativo de nossa localização numa etapa em relação a qual existe consciência de transição: a consciência de encontrar-se em uma encruzilhada cultural na qual o velho já não vale e se anda em busca do novo" (TAPIAS, 1996, p. 20).
} 
proposição de Arendt não elimina o consenso, visto que a igualdade entre os homens torna isso possível, mas um consenso que não elimine a possibilidade do dissenso. Numa democracia formal, das instituições e do sufrágio, é fundamental que haja a possibilidade do dissenso, representado pela defesa da dignidade humana, pelo respeito aos Direitos Humanos e pela existência de limites ao exercício dos poderes (políticos e econômicos) e ao arbítrio que, no caso brasileiro, se referem aos Direitos e Garantias Fundamentais: os artigos que compõem o Título II da Constituição Federal. A ausência de limites ao poder inviabiliza qualquer pretensão democrática.

Pretendia-se, ao conferir limites rígidos ao poder, inclusive ao poder das maiorias de ocasião (maiorias, por vezes, forjadas na desinformação produzida pelos meios de comunicação de massa), superar a concepção empobrecida e meramente formal de democracia que se identifica com a submissão ao princípio da maioria para a tomada de decisões (CASARA, 2018b, p. 12).

A regra da maioria pode ser um elemento de eficácia para as decisões políticas em sociedades plurais, mas há mecanismos contramajoritários para evitar que a maioria destrua ou tiranize a minoria, possibilitando o dissenso e a ação política. Pois se todos fossem iguais, inclusive em seus "interesses" e "opiniões", não haveria razão para a existência da política como esfera de ação. As maiorias, ademais, podem representar um consenso, embora não sejam autorizadas a eliminar a ação e o espaço público, lugar do aparecimento da unicidade, donde o consenso deve ser o resultado dos debates e da ação, não da violência, propaganda e intimidação. "Somente o homem pode expressar esta distinção e distinguirse, e apenas ele pode comunicar seu próprio eu e não simplesmente algo: sede ou fome, afeto, hostilidade ou temor" (ARENDT, 2005, p. 206).

Daí o receio em relação às maiorias e a defesa dos limites aos poderes. Sede, fome, afetos, medo, raiva, ódio, são atributos da espécie, não dos indivíduos ou das singularidades. Evidenciam "o que" têm ou são os homens: sedentos, famintos, medrosos, raivosos, odientos, mas não "quem são". "Quem é você?" Segundo Arendt (2005, p. 208), "este descobrimento de quem é alguém está implícito tanto em suas palavras como em seus atos", e a revelação acontece num espaço de igualdade e liberdade, o espaço público que assegura a realidade do mundo e de nós mesmos, na medida em que a aparência constitui a realidade (ARENDT, 2005, p. 71). "Público", para Arendt, significa, portanto, a esfera da aparência e, também, o próprio mundo, "enquanto é comum a todos nós e diferenciado de nosso lugar possuído privadamente nele" (ARENDT, 2005, p. 71-73).

A indistinção entre "público" e "privado" atinge o ápice no Totalitarismo, numa "politização total" da existência. Hitler, por exemplo, não tinha vida privada. Ou melhor, sua vida privada era um vazio. Além das frustrações oriundas de constantes fracassos, após ascender como líder de um movimento, viveu exclusivamente para o papel que desempenhou:

Não havia recolhimento para uma esfera fora do político, para uma existência mais profunda que condicionasse seus reflexos públicos. Não é que sua 'vida privada' tenha se tornado parte de sua persona pública [...]. Na verdade, Hitler 'privatizou' a esfera pública. 'Privado' e 'público' fundiram-se completamente e se tornaram inseparáveis. O ser de Hitler inteiro subordinou-se ao papel que ele desempenhava com perfeição: o de 'Führer' (KERSHAW, 2010, p. 29-30).

No Brasil, Bolsonaro não se subordinou ao papel de presidente e o tornou seu. Pelo contrário, a Presidência da República (instituição) se tornou Bolsonaro, o qual gere os assuntos políticos como particulares: as intrigas palacianas, as reformas no Palácio do Planalto, as respostas nas redes sociais aos seus desafetos representam não a postura de um indivíduo que assume a responsabilidade política como governante, mas um ente privado com seus interesses que transforma o posto em seu e administra o público como familiar.

O "privado" significa estar privado de coisas essenciais para a vida humana: "estar privado da realidade proveniente de ser visto e ouvido pelos demais, estar privado de uma $<<$ objetiva $>>$ relação com os outros que provém de encontrar-se relacionado e separado deles através do mundo comum" (ARENDT, 2005, p. 78). Não se pode saber se o presidente está privado da realidade por utilizar da mentira como política ou por alienação, visto que a diferença sempre é um problema, algo que lhe causa 
ansiedade. De todo modo, esse alheamento não lhe permite ter acesso à realidade, que se constitui na medida em que os seres humanos intercambiam entre si suas percepções e as corrigem. Por outro lado, mesmo privatizando a Presidência da República, Bolsonaro não vive uma vida privada no sentido de que ela oferece uma proteção ao mundo, um lugar em que, separado do mundo e dos outros, é possível pensar, refletir sobre tudo aquilo que acontece e sobre os próprios pensamentos. "Uma vida que transcorre em público, na presença dos outros, se faz superficial” (ARENDT, 2005, p. 86), pois se separa da profundidade que só o pensamento pode alcançar. O pensamento tenta ir à raiz das questões, busca os sentidos daquilo que acontece ou dos próprios pensamentos, mas em relação ao mal, se depara com a superficialidade e se frustra porque só encontra banalidade (BERNSTEIN, 2006, p. 237).

Sobre essa temática, a "banalidade do mal" e a relação com o pensamento (pode o pensar ser um antídoto à banalidade do mal?), Arendt escreve sua última grande obra, A vida do espírito. O impulso para o estudo foi o julgamento de Eichmann em Jerusalém, publicado na forma de livro posteriormente. Para a autora, "os atos eram monstruosos, mas o agente - ao menos aquele que estava em julgamento era bastante comum, banal, e não demoníaco ou monstruoso" (2009, p. 18). Isso se verificava pela incapacidade de pensar, ausência de convicções ideológicas ou de motivações más. Tratava-se de irreflexão, não estupidez (ARENDT, 2009, p. 18). A incapacidade de pensar, por sua vez, se revelava na utilização de clichês, frases feitas, adesão a códigos de conduta que possuem a função de "proteger-nos da realidade, ou seja, da exigência de atenção do pensamento feita por todos os fatos e acontecimentos em virtude de sua mera existência (ARENDT, 2009, p. 19) ${ }^{6}$. A ausência de pensar, de enfrentar os fatos e as crises não com preconceitos e pré-juizos, como argumentei anteriormente, também caracterizavam Hitler, um indivíduo com poucos atributos intelectuais e sociais, incapaz de uma amizade genuína, embora um leitor frequente. Mas, "ler para ele não era uma busca de iluminação ou aprendizado, mas de confirmação de preconceitos" (KERSHAW, 2010, p. 84), ou seja, era incapaz de realizar qualquer experiência, inclusive de pensamento, de refletir e de se colocar no lugar dos outros.

É preciso atentar que nem Hitler nem Bolsonaro teriam êxito político noutras condições. Se Hitler era um orador eficaz, o mesmo não se pode dizer do presidente brasileiro. Ambos tiveram êxito, guardadas as distinções circunstanciais, não criando nenhuma ideia, doutrina ou crença, mas combinando diagnósticos e receitas simples para problemas complexos, jogando com o ódio e o ressentimento disseminados na sociedade. "O que Hitler fazia era propagar ideias não originais de um modo original. Ele dava voz a fobias, preconceitos e ressentimentos como ninguém [...]. O que contava não era o que ele dizia, mas sim como dizia" (KERSHAW, 2010, p. 113-114, grifos do autor). Em relação ao brasileiro, a originalidade não ocorreu por algum atributo seu, mas por um modo distinto de propagar ideias: os "memes" e uma rede de notícias falsas na internet.

O "discurso" de Bolsonaro e seus apoiadores se baseia em nossa tradição de ódio e violência que repercute nas simplificações das "soluções" aos problemas complexos. Ao aumento da violência, o armamento da população e um pacote de lei denominado "Anticrime"; à elevação na taxa de desemprego e à crise de arrecadação do Estado, uma reforma trabalhista e uma reforma previdenciária; a (suposta) incapacidade do Estado de financiar obras públicas, a saúde e a educação é respondida com a responsabilização ao Partido dos Trabalhadores. Nesses poucos exemplos interpreto que há a evidenciação de uma preponderância da violência estatal e da violência como linguagem expressas nas falas dos representantes e nas ações do governo, especialmente pela ênfase do Sistema de Justiça Criminal em detrimento de outros segmentos da Justiça e/ou outras formas de se entender a "Justiça".

Esse é um dos elementos importantes da "pós-democracia", na qual há a flexibilização dos limites aos poderes e aos arbítrios e a concomitante utilização da Justiça para a "gestão dos indesejáveis". Para Casara (2018a), o espaço público, a linguagem e as ações do Estado (e dos cidadãos!) não valoram mais a liberdade, mas a prisão num conflito valorativo. "O Sistema de Justiça Criminal é o principal laboratório para testar a aceitação social de medidas autoritárias" (CASARA, 2018a, p. 92), e o ideal de

\footnotetext{
${ }^{6}$ Seria preciso um estudo mais detalhado com os indivíduos citados na nota de rodapé 2, acerca do funcionamento das instituições democráticas. A hipótese que me parece plausível é um conjunto de ausência de pensamento (o que não significa ignorância) e oportunismo político, dentro de um projeto coerente com a "racionalidade neoliberal", na qual a democracia é atacada ou esvaziada de seu sentido político.
} 
"Justiça" é substituído pelo de "Poder" ou, para utilizar os conceitos de Hannah Arendt, de violência e submissão. O que especifica o Sistema de Justiça Criminal na "Pós-Democracia" "não é o autoritarismo ou mesmo uso seletivo do poder penal, e sim a ausência de limites ao exercício desse poder", argumenta Casara (2018a, p. 95).

Em 2019, o então Ministro da Justiça, Sérgio Moro, apresentou um anteprojeto de Lei denominado "Anticrime" à Câmara dos Deputados. Dentre algumas medidas, duas merecem apreciação: a) sobre as penas privativas de liberdade, que autoriza a prisão em segunda instância, alterando a Lei de Execução Penal no Art. 105; b) a ampliação da compreensão de "legítima defesa" dos agentes de Estado, com a possibilidade de suspensão da pena para os "excessos" oriundos de "execrável medo, surpresa ou violenta emoção", alterando o artigo 23 do Código Penal. Tais alterações podem ser interpretadas na perspectiva "Pós-Democrática" da ausência de limites aos poderes e aos arbítrios, neste caso, do Estado em nome da "racionalidade neoliberal". No que concerne à medida "a", trata-se de valorar a prisão, a detenção e não a liberdade do réu. Ou seja, atenta aos Direitos e Garantias Fundamentais sob a ideologia da eficácia do encarceramento como forma de resolver e conter problemas sociais. O Artigo $5^{\circ}$ da Constituição prefigura a defesa da liberdade individual, que no inciso LVII, "ninguém será considerado culpado até o trânsito em julgado de sentença penal condenatória" garante aos cidadãos a presunção de inocência e, portanto, a não antecipação da pena ou da culpa. "Na pós-democracia, desaparece a noção do dever do agente estatal de garantir direitos fundamentais" (CASARA, 2018a, p. 111). A prisão, no Estado Democrático de Direito, é a exceção, e a liberdade é a regra. Na "pós-democracia", a prisão é a regra, e a liberdade a exceção. E, em relação à presunção de inocência, o juiz deve partir do pressuposto de que o cidadão é inocente e só prova contrária é que resulta na condenação (CASARA, 2018a, p. 154). Alguns dos julgamentos de Sérgio Moro, quando atuava como Juiz Federal, especialmente no contexto da operação Lava Jato, representaram uma inflexão nesse princípio.

Como os agentes do Estado não principiam suas ações pela defesa dos Direitos e Garantias Fundamentais, é lógico, para o anteprojeto do Ministério da Justiça, proteger não ao cidadão e seus direitos mas ao agente do Estado Penal, conforme a alteração do item "b". O Poder Judiciário (considerando o antecedente do ex-Ministro Sérgio Moro como Juiz Federal), e o Estado de modo geral, não se pautam pela ideia de "dever", mas "poder" (ou violência), para consolidar-se e atender aos anseios de uma maioria, produzida pelo espetáculo. "A atuação dos magistrados passa a ser a do empresário pautado pelo desejo das maiorias, e com isso, ficam inviabilizados o espaço e os direitos daqueles que não atendem à lógica neoliberal" (CASARA, 2018a, p.132). Há a ruptura com os limites ao exercício do poder e com a natureza contra majoritária do Poder Judiciário.

A definição da "pós-democracia" como ausência de limites é pensada por Casara (2018a e 2018b) referindo-se aos estudos de Jean-Pierre Lebrun em Um mundo sem limites (2004). Para o autor francês, houve uma "evolução" no significado da "família", em relação aos "papéis", expectativas e atuação dos indivíduos que a compõe. A "família" representa o "caldeirão da vida social", o lugar em que se prepara o futuro sujeito, em suma, um espaço de formação. A "evolução" gera uma crise na qual há o declínio do "pai", isto é, da "posição de terceiro" e de autoridade. A "família" não é mais regida como instituição, mas por um pacto privado, em que as tensões são resolvidas por negociações internas sob a ideia organizativa de uma "família igualitária". Com a ciência biológica, o genitor se confunde com o pai na ordem da filiação. O que em princípio é um ganho, a expansão da igualdade, acarreta danos profundos para a formação dos sujeitos (LEBRUN, 2004, p. 14). Ademais, Arendt considera que a igualdade é um atributo exclusivo da política, não da esfera social ou privada da família.

A função do "pai", cuja decadência está relacionada a ausência de limites, se fundamenta no simbólico e não no biológico. Para Lebrun (2004, p. 27, grifos do autor), o pai

é o primeiro estranho, que é e sempre será o estranho no mais familiar, e isso para além de quaisquer afinidades e companheirismos que possam existir entre o pai e o filho. É essa alteridade irredutível que o define e do qual ele nunca se afastará inteiramente; ele é e permanecerá sendo outro radical. 
O "pai" é um outro que rompe com o "outro mesmo" da mãe, instaurando a linguagem, o simbólico, em suma, o limite. A criança precisa se separar da mãe para se formar sujeito, isto é, impor seu próprio desejo sobre o desejo da mãe. Evidentemente que a criança inicia o processo de individuação com a mãe, desde que a relação seja saudável. Mas é o "pai", o "outro radical", que institui a alteridade (LEBRUN, 2004, p. 27) na medida em que interdita o domínio da mãe e da "mesmidade", da identificação do desejo com o desejo da mãe ou do desejo pela mãe. "Podemos perfeitamente entender 'o pai' como aquele que vem dizer 'não, ela não é tudo o que você diz dela!'” (LEBRUN, 2004, p. 32), estabelecendo um limite, apresentando-se como outro e permitindo à criança ser desejante e si mesma. A mãe oferece um primeiro significante do "outro" e de o que é a criança, e o "pai" os relativiza, introduzindo o registro assimétrico do terceiro (LEBRUN, 2004, p. 35). A mãe já tem "dono" e não há esperança de extrair-se gozo daí. Mas é preciso que a mãe sustente o lugar do pai, autorize a intervenção para que o "pai real" intervenha, ratificado, igualmente, pelo social (LEBRUN, 2004, p. 42).

Assim, o significante "pai” impõe limites à liberdade e à opressão (da criança e da mãe), pois há um outro que é desejante e livre e não se inscreve nas representações maternas. O pai "interdita a pulsão da criança, ao mesmo tempo que faz a mãe perceber que o filho não é uma parte dela" (CASARA, 2018b, p. 51). As origens da "pós-democracia", bem como a possibilidade dos "antídotos" podem ser buscados na formação e na educação, no processo de subjetivação e nas condições de possibilidade para a singularidade. Se a "pós-democracia" só é possível numa "sociedade sem limites", da ausência de limites aos arbítrios e ao poder, há uma relação entre o "neoliberalismo" e o "totalitarismo", pois o sistema totalitário se constitui na massa que deseja o desejo do líder, o qual afirma "a sociedade sou eu" (LEBRUN, 2004, p. 85). O dirigente se apoia na massa ao mesmo tempo em que organiza a sociedade sem classes, na qual tudo é política, isto é, o partido penetra em cada domínio da existência e a abolição da metáfora paterna, fazendo desaparecer a alteridade do pai. Trata-se do abuso do poder materno. Para Lebrun (2004, p. 90), "a figura de Hitler deveria antes ser relacionada com a mãe onipotente que com o que se chama comumente de pai tirânico".

Hitler era "mãe", pois todas as referências e desejos eram seus, desejos desejados pelas massas. Os nazistas se ocuparam não apenas de destruir a realidade, mas de criar as condições para que a ideologia se tornasse real, atuando como se de fato houvesse um complô mundial judaico ou, em determinados círculos mais sensíveis aos ataques antissemitas, Hitler reduzia os problemas da Alemanha ao "marxismo", "uma simplificação conveniente para detratar a democracia de Weimar" (KERSHAW, 2010, p. 211). "As pessoas que começaram a afluir aos discursos de Hitler em 1919 e 1920 não eram movidas por teorias refinadas. Para elas, o que funcionava eram slogans simples que acendessem os fogos da raiva, do ressentimento e do ódio" (KERSHAW, 2010, p. 115). O que mais pode acender a raiva, o ressentimento e o ódio do que o "terrível outro"? O não controlado, não adaptado, não assimilado, o outro desejante? O ódio, em especial, é dirigido ao simbólico antes que ao "real", ao furo que se localiza na consciência narcisista: "a existência do outro gera uma ameaça à imagem que a pessoa que odeia tem de si” (CASARA, 2018b, p. 33). Como explicar o ódio aos pobres, aos negros, aos povos originários, aos gays, às mulheres, aos comunistas? O sistema totalitário precisa destruir a alteridade, colocando-a na posição de um "mal absoluto" que deve ser extirpado, destruído, exterminado. Assim, o ódio se vincula à mentira e à alucinose, ou seja, "uma distorção efetiva da capacidade de pensar fundada na necessidade de saturar a realidade com desejos que não suportam frustração, bem como no impacto corrosivo dos mecanismos psíquicos ligados ao ódio sobre o próprio pensamento" (AB’SÁBER, 2018, p. 129, grifos do autor).

Arendt (2012, p. 435), por sua vez, argumenta que para os nazistas o mal exercia uma atração mórbida, independente do interesse pessoal, e o movimento exigia e se sustentava num altruísmo dos adeptos, isto é, um conformismo total e a disponibilidade de parecer ser necessário. O que move as massas não é a convicção ou o idealismo, mas a insatisfação, o desespero, a descrença nas esperanças partidárias e, no que diz respeito ao "homem massa", a "compreensão" de ter fracassado como indivíduo e estar sofrendo uma injustiça, a amargura egocêntrica, a perda do interesse em si mesmo, a indiferença, o desprezo geral pelas regras do bom senso, o autoabandono e a solidão. Para Arendt (2012, p. 446), “a principal característica do homem da massa não é a brutalidade nem a rudeza, mas o seu isolamento e a sua falta de relações normais". O Partido Nazista (NSPDA) não era uma representação de classe, mas 
da nação (KERSHAW, 2010, p. 234). No Brasil, nas últimas campanhas eleitorais (2014, 2016 e 2018) era frequente candidatos não se apresentarem "nem como de direita nem como de esquerda", quando representavam interesses conservadores ou da extrema direita. No último pleito, houve uma "guinada" no discurso. Não se tratava mais de "nem de esquerda nem de direita", mas de representar uma abstração fantasiosa: "Brasil acima de tudo, Deus acima de todos".

No Brasil, houve apoio da população à aprovação da PEC 241, do Teto de Gastos, e mesmo uma parcela significativa de eleitores do atual presidente defende as medidas de austeridade, de corte de gastos sociais que afetam diretamente a saúde, a educação e o emprego, ou ainda, a adesão a clichês acerca da "ameaça comunista" ou do "bolivarianismo". Todos conhecemos pessoas que votaram e apoiam (ou apoiaram) um governo que atua contrariamente aos seus interesses imediatos. Isso pode ser uma reação às políticas sociais de inclusão dos mais pobres na economia, especialmente pela "racionalidade neoliberal" que considera os homens como seres racionais egoístas, dispostos a "parasitar" o Estado e a não atuar economicamente e produtivamente, a não buscar empreender sem as coações do Estado e das necessidades da competição. Disso deriva a crítica à ampliação da participação popular nas decisões políticas, taxada de bolivarianismo pela direita brasileira, segundo uma visão elitista da democracia: "o que está sendo dito é que a preservação do Estado de Direito, da ordem e da estabilidade requer cidadãos que se comportem como espectadores enquanto os representantes governam” (FRATESCHI, 2018, p. 156-157). Por outro lado, pode ser também alienação segundo o que escrevi acima, sujeitos que se dispensaram da capacidade de pensar sobre o que lhes acontece ou o que fazem, são indiferentes ao que se passa a si e aos outros, não compondo uma classe ou participando de partidos políticos "tradicionais", que são limitados por objetivos determinados e atingíveis (ARENDT, 2012, p. 442). As massas estão fora de uma representação política normal e "constituem a maioria das pessoas neutras e politicamente indiferentes, que nunca se filiam a um partido e raramente exercem o poder de voto" (ARENDT, 2012, p. 439).

Nas eleições presidenciais de 2018, segundo dados do Tribunal Superior Eleitoral, no primeiro turno, houve $20,33 \%$ de abstenções, $2,65 \%$ de votos brancos e $6,14 \%$ de nulos, totalizando $29,12 \%$ de eleitores. No segundo turno, houve pouca alteração: $21,30 \%$ de abstenções, $2,14 \%$ de votos brancos e 7,43\% de votos nulos, totalizando 30,87\%. É possível afirmar que os eleitores que compõem tal grupo pertencem a uma massa? Sim, se se tratar de indiferentes, desinteressados consigo mesmos e com o "público", desesperançados e desconfiado sem relação aos "políticos profissionais" e aos partidos políticos, e não articulados nem com um interesse comum que os vincularia entre si num agrupamento. Talvez esse grupo pudesse ser explicado a partir da lógica de que as eleições não alteram suas vidas privadas e nem representam os signos de sucesso possíveis ou esperados, e que, independente do agrupamento político de turno, as coisas serão sempre as mesmas. No sistema eleitoral brasileiro, eles fariam diferença se participassem do pleito; logo, o não comparecimento não é isento de responsabilidade. Por outro lado, apesar de um potencial descontentamento, é razoável pensar que o candidato Bolsonaro angariasse os votos dos descontentes e descrentes com a política "tradicional" e os grandes partidos, dando vOz ao ressentimento, ao ódio e às frustrações ao usar a violência e a força como linguage ${ }^{7}$, como antidiscurso e, portanto, como antipolítica, porque nega o outro enquanto alteridade ou, em termos arendtianos, singularidade. Para Arendt (1993), o sentido da política é a liberdade, isto é, a possibilidade de agir, de iniciar, de começar, de romper com as expectativas e com a História e instaurar o novo. Assim, a política é o espaço do "milagre", e uma política considerada apenas como resolução das necessidades liquida a própria política e se transforma em falta de sentido (ARENDT, 1993, p. 119). A ação, então, acontece especialmente no "espaço-entre", na política, e diz respeito ao "mundo".

\footnotetext{
${ }^{7}$ No Acre, em campanha eleitoral no ano de 2018, Bolsonaro disse: “vamos fuzilar a petralhada aqui do Acre, heim?", enquanto utilizava um tripé de câmera para simular uma metralhadora (https://exame.abril.com.br/brasil/vamos-fuzilar-apetralhada-diz-bolsonaro-em-campanha-no-acre/). Em 2003, Bolsonaro falou à Deputada Maria do Rosário (PT/RS) que não a estupraria porque ela não merecia, episódio repetido em 2014 (https://oglobo.globo.com/brasil/stf-mantem-pagamentode-indenizacao-de-bolsonaro-maria-do-rosario-23464003). Ou a "homenagem" ao torturador Carlos Alberto Brilhante Ustra, por ocasião do julgamento do processo de Impeachment na Câmara dos Deputados em 2016. e afirmou, em 2019, que Ustra é um herói nacional (https://veja.abril.com.br/politica/bolsonaro-afirma-que-torturador-brilhante-ustra-e-um-heroinacional/).
} 
Bolsonaro e seus discursos evidenciaram não uma "política da necessidade", isto é, de projetos para atender as demandas vitais, mas de destruição, de ruptura, de contrariedade com "tudo isso que está aî", mesmo que se tratasse de um engodo, uma vez que ele fazia parte, como deputado federal pelo Estado do Rio de Janeiro, disso tudo que estava aí. O mais importante não era o que ele dizia, mas como dizia e o efeito que produzia. A combinação de uma fantasia masculina ${ }^{8}$ com o culto à violência, a escolha do inimigo conforme o momento e a conveniência (o Partido dos Trabalhadores, o Comunismo, a Venezuela, a China, a esquerda), a repetição de uma concepção maniqueísta e, portanto, simplista da realidade eram (e continuam sendo) componentes de sua atuação, que contribui para a compreensão do que denomino como "Pós-Democrático", pois destrói a ação, o discurso e a possibilidade de aparecer como singular. Daí a necessidade de constantemente interpretar um papel, projetar um cenário. Como Hitler, Bolsonaro é um agitador, um antidemocrata, enaltecedor da violência e da força. Distinto do alemão, é incapaz de organizar as massas, mau orador e focado unicamente no culto a si mesmo como "mito". Hitler contava com o suporte de um partido que contribuía ao culto de sua personalidade. Bolsonaro ganhou a eleição no PSL (Partido Social Liberal), que dispunha de 241.152 filiados em outubro de 2018, com um programa de governo de poucas ideias e propostas, mas com uma lógica neoliberal. Isso poderia contribuir para aumentar a mobilização, abrangendo mais pessoas. Mas, depois da eleição, não foi isso que aconteceu. Bolsonaro apostou na crise como forma de governo, mas quando a crise não foi criada por si mesmo, pelos seus filhos ou aliados, a ideia do "mito" feneceu.

\section{AS POSSIBILIDADES DA EDUCAÇÃO NA PÓS-DEMOCRACIA}

Queria apenas tentar viver aquilo que brotava espontaneamente de mim. Por que isso me era tão difícil? (HESSE, 2000, p. 9).

"Pós-Democracia" ou "Pós-verdade"? Qual conceito caracteriza com mais propriedade nosso contexto? Ambos se relacionam, embora a "Pós-Verdade" esteja englobada na "Pós-Democracia", na medida em que entendo o segundo como "ausência de limites". A "Pós-verdade" se caracteriza pela indistinção entre verdade e mentira em favor das emoções e da mensagem. Há em todos os segmentos sociais, espaço público e privado, "um império sem argumentos. Um império de quem melhor sabe exercer a violência" (SANZ, 2017, p. 52). Se não há mais a distinção entre verdade e mentira e o interesse dos "gestores" e "governantes" é em dizer o que as massas de consumidores narcisistas esperam ou de dizer de um modo que seja aceito pelo simples fato de ser dito, não há democracia possível, pois a democracia exige a política como condição de possibilidade, isto é, a ação em comum e a formação da opinião. A esfera dos assuntos humanos se constitui de fatos e eventos, "o resultado invariável de homens que vivem e agem conjuntamente" (ARENDT, 2007, p. 287), e ambos são mais frágeis que axiomas, descobertas e teorias, pois poderiam ser de outro modo, dado que os homens são capazes de ação.

Mas a "pós-verdade" não acontece apenas no e sobre os assuntos humanos. Também afeta as "verdades racionais" e científicas. Na crise sanitária, provocada pelo COVID-19, Bolsonaro insistiu em rechaçar a gravidade da pandemia" e alardeou um medicamento, a cloroquina, como a panaceia ${ }^{10}$,

\footnotetext{
8 "Para Hitler, as mulheres eram um objeto, um adorno num 'mundo masculino"' (KERSHAW, 2010, p.250) e as massas eram tratadas como feminino (KERSHAW, 2010, p.253). No governo de Bolsonaro, o ministério é composto majoritariamente por homens brancos e heterossexuais. Sobre sua filha, disse, em palestra na Hebraica: "eu tenho cinco filhos. Foram quatro homens, a quinta eu dei uma fraquejada e veio uma mulher" (https://revistaforum.com.br/noticias/bolsonaro-eu-tenho-5filhos-foram-4-homens-a-quinta-eu-dei-uma-fraquejada-e-veio-uma-mulher-3/).

9 "Bolsonaro minimiza uma vez mais a gravidade da pandemia" (https://www.dw.com/es/bolsonaro-minimiza-una-vezm\%C3\%A1s-la-gravedad-de-la-pandemia/a-52934378). "Bolsonaro minimiza e diz que coronavírus "não é isso tudo"” (https://www.gazetadopovo.com.br/republica/breves/jair-bolsonaro-minimiza-pandemia-coronavirus/).

10 "Bolsonaro diz que médicos escondem o uso de cloroquina" (https://www.poder360.com.br/coronavirus/bolsonaroinsinua-que-medicos-escondem-uso-de-cloroquina/). "Bolsonaro reforça eficácia da cloroquina e alfineta governo Dória" (https://noticias.r7.com/brasil/bolsonaro-reforca-a-eficacia-da-cloroquina-e-alfineta-governo-doria-08042020). 
mesmo sem um embasamento científico razoável, sustentável e de acordo com experiências em outros países. Não importa qual seja a intenção. O importante é a desconsideração da distinção entre verdade e mentira, os efeitos para a existência comum e a continuidade da política. De algum modo, isso se articula com a "racionalidade neoliberal", na produção de um imaginário que procura confundir a realidade com as ficções a fim de desativar o poder desestabilizador ou transformador da "verdade", da Ciência, da Literatura, das Artes.

Em termos de neoliberalismo, "O problema não é que os macroeconomistas digam coisas que são inconsistentes com os fatos. O problema de verdade é que a outros economistas dá no mesmo que aos macroeconomistas os fatos não importam" (ESTEFANÍA, 2017, p. 80). As "soluções" às crises econômicas exigem, como qualquer crise, o enfrentamento dos fatos, sejam quais forem, e respostas contundentes às questões que elas permitem realizar. Por exemplo, qual a finalidade da economia? Qual a tarefa do Estado frente a uma crise econômica? Quais os fatores que contribuíram com a crise? Qual a essência da economia? Os ideólogos da "pós-verdade" ignoram os fatos e agravam a crise com medidas de austeridade, ou são alucinados, isto é, carecem da capacidade de pensar, de imaginar.

Para Arendt (2007, p. 325), "conceitualmente, podemos chamar de verdade aquilo que não podemos modificar; metaforicamente, ela é o solo sobre o qual nos colocamos de pé e o céu que se estende acima de nós". A verdade, portanto, é um limite para o "tudo é possível" "11 e uma garantia da política e da democracia. Sem a verdade não há debate, discussão, comunicação possível. Há apenas violência, isolamento e solidão. É a partir da verdade que formamos as opiniões, ajustando-as aos pontos de vista dos demais e constituindo um "senso comum", isto é, o senso de pertencimento à comunidade humana. Sem a verdade, racional (científica, matemática e filosófica) e factual, não há "mundo comum" e tudo se perde em "narrativas" ou disputas ideológicas no qual o mais forte vence e impõe sua visão de mundo.

Num estudo sobre a ideologia nos livros didáticos israelenses, Nurit Peled-Elhanan (2019) considera que a educação propaga uma visão idealizada de Israel como uma sociedade judaica, branca, moderna, ocidental e democrática contra inimigos identificados como "problema" ou "árabes" - um rótulo que serve para legitimar a narrativa sionista segundo a qual os palestinos não constituem uma nação específica, mas pertencem a um grupo maior que possui 21 Estados (PELED-ELHANAN, 2019, p. 85-86). A "idealização" é apresentada como realidade e como projeto, pois os judeus de Israel são majoritariamente orientais, e encobre atitudes racistas e heterofóbicas com judeus não ocidentais, palestinos e árabes. A "visão" dos palestinos sobre o conflito é representada como visão ou "consciência", não como um fato ${ }^{12}$. E os "fatos" apresentados aos alunos são construções que eliminam o outro como capaz de fala e significação. Em termos de educação democrática, "democracia" significa que qualquer um pode falar e agir, e é na fala e na ação que se constituem os indivíduos democráticos (MASSCHELEIN; SIMONS, 2014, p. 89). A educação israelense, deduzindo dos estudos de PeledElhanan (2019), não é democrática porque exclui da fala e da ação, da História e da verdade, os palestinos, árabes, beduínos e minorias que vivem sob o Estado de Israel. Os livros didáticos, assim, naturalizam silenciamentos e marginalizam os indesejáveis: "A marginalização dos árabes é enfatizada em todos os livros didáticos de geografia: cidades e aldeias árabes no interior de Israel estão ausentes dos mapas e o mundo-da-vida palestino não aparece nos textos" (PELED-ELHANAN, 2019, p. 147). No Brasil, os silenciamentos acontecem quando câmaras municipais ou estaduais tentam aprovar projetos de lei que excluem o ensino e o estudo da "identidade de gênero", silenciando e apagando simbolicamente minorias que não se veem e não se identificam com o modelo binário tradicional.

\footnotetext{
${ }^{11}$ Referência à epígrafe da terceira parte de Origens do Totalitarismo, "os homens normais não sabem que tudo é possível”, de David Rousset (ARENDT, 2012, p. 413).

${ }^{12}$ Como exemplo, a autora apresenta um fragmento do livro didático de História The 20th Century: "Na consciência dos árabes, a guerra de 1948 e suas consequências são entendidas como 'Shoá'. Os árabes-palestinos não apenas perderam sua terra, mas tornaram-se uma nação de refugiados. Em oposição, para os israelenses, a fuga dos árabes resolveu um terrível problema demográfico, e até mesmo uma pessoa moderada como [o primeiro presidente] Weizmann falou a respeito disso como um 'milagre'. E de fato desde cedo era evidente que Israel não ia permitir o retorno dos refugiados. [...] Os líderes árabes escolheram usar os refugiados como um aríete contra Israel” (apud PELED ELHANAN, 2019, p. 116, grifos da autora).

Educação em Revista|Belo Horizonte|v.37|e25258|2021
} 
Os livros didáticos estudados reforçam preconceitos e racionalizam discriminações, criando, por meio da educação, a impossibilidade de uma resolução a um conflito, pois não há uma verdade sob a qual todos os concernidos possam assentar-se e começar a dialogar. Os fatos favoráveis aos palestinos são transformados em "meras opiniões", anulando a priori qualquer discussão, debate e senso comum. Ademais, os livros didáticos israelenses utilizam estratégias "políticas" (próprias da administração estatal) de representação negativa - impessoalização, generocização, funcionalização, demonização e naturalização da discriminação (PELED-ELHANAN, 2019, p. 95-105) - e "linguísticas" na composição dos livros didáticos - representações visuais excludentes, omissão de territórios, cultura e atividades árabes, disposição e destaque de layouts que favorecem à narrativa sionista-israelense, etc. Para Arendt (2006, p. 16), as mentiras são muito mais plausíveis,

uma vez que o mentiroso tem a grande vantagem de saber de antemão o que a plateia deseja ou espera ouvir. Ele prepara sua história com muito cuidado para consumo público, de modo a torná-la crível, já que a realidade tem o desconcertante hábito de nos defrontar com o inesperado para o qual não estamos preparados.

Assim, a mentira precisa constantemente adaptar-se à realidade e, quando isso acontece, desaparece por completo a verdade da vida pública, o fator de estabilidade aos assuntos humanos. "Os homens atuantes, quando se sentem donos de seus próprios futuros, ficarão eternamente tentados a se fazerem donos do passado também", argumenta Arendt (2006, p. 20). Daí a relevância de pensarmos a educação no sentido da "transmissão", daquilo que os alunos herdarão e que serão iniciados e introduzidos sob os cuidados do adulto, o representante do mundo. Porém, o que pode ser um ganho para a idealização política pode, também, ser contraproducente, dado que se não há mais verdade e só narrativa, a narrativa apresentada como verdade não é mais, nem menos, que uma narrativa. O "outro" continua a existir e a afrontar a necessidade de compreensão ${ }^{13}$. Conclui Peled-Elhanan (2019, p. 131): “o que determina o conteúdo factual desses livros não é informação arquivística, mas a voz ideológica para a qual têm de servir de ventríloquos e a narrativa 'conscientemente fraudulenta' que têm de transmitir'.

Educacionalmente, a verdade funda a relação pedagógica quando compreendemos que a escola deve ensinar como o mundo é (ARENDT, 2007, p. 246). Isso implica dizer que não interessa muito como desejaríamos que fosse o mundo, nem se nos envergonhamos por ele estar em ruínas. A educação diz respeito a dar condições de possibilidade para que as novas gerações adentrem ao mundo e saibam situar-se. Assim, o conhecimento, que almeja a verdade, é um aspecto fundamental daquilo que legamos às crianças e jovens. Ademais, a educação consiste numa constatação da ignorância, do que não sabemos, do saber que não se sabe para a busca pelo saber e a abertura ao mundo, à experiência e ao outro.

Ser humano consiste na vocação de compartilhar o que sabemos entre todos, ensinando aos recém chegados ao grupo quanto devem conhecer para fazer-se socialmente válidos. Ensinar é sempre ensinar ao que não sabe e quem não indaga, constata e deplora a ignorância alheia não pode ser professor, por muito que saiba (SAVATER, 2011, p. 26-27).

O conhecer, como atividade, se inicia no momento da constatação da ignorância. O professor, como mediador entre o "novo" e o "velho", a "família" e o "mundo", principia a educação pela constatação da ignorância ao mesmo tempo em que atenta à igualdade constitutiva da escola - todos são capazes de aprender - e essa igualdade é uma das condições para a cidadania e a democracia. É revolucionária porque a democracia não é o poder dos (mais) qualificados e (mais) competentes (MASSCHELEIN; SIMONS, 2014, p. 89). O “espaço" do poder está "vazio" e, em termos arendtianos (2005), é constituído quando os seres humanos atuam em conjunto, independentemente de sua cultura,

\footnotetext{
13 Nos livros didáticos analisados por Peled-Elhanan (2019, p. 105), os “outros" (palestinos e árabes-palestinos) sofrem também um "racismo visual" quando não são representados em contextos reais, sendo retratados como agentes imorais ou criminosos, apresentados como um grupo homogêneo, com conotações culturais negativas ou imagens espaciais que os objetificam ou tornam sua existência abstrata.
}

Educação em Revista|Belo Horizonte|v.37|e25258|2021 
história, condição econômica, filiação ou status social. Tal é o "poder dos sem poder" que escreve Václav Havel.

A educação, na "pós-democracia", deve atentar à verdade e ao conhecimento, propiciando às novas gerações o acesso a aquilo que fundamenta o conhecimento e não apenas a discursos sobre a verdade, o mundo e/ou a natureza. Ter acesso à verdade, ao mundo e à natureza apenas pelos livros didáticos não é suficiente para que as crianças e jovens adentrem ao mundo adulto. Daí a confusão entre verdade e opinião ou a transformação de toda verdade em opinião. A Biologia, a Química, a Física precisam apresentar as partes do mundo/natureza que lhe cabem, introduzindo os estudantes nas teorias, consensos e dissensos da Ciência, por meio de experimentos, observações, comparações e todos os elementos de provas aceitos pela comunidade científica. A História, tratando da verdade factual, não pode ser ensinada exclusivamente por meio do discurso do professor e da leitura do livro didático. A verdade factual se sustenta em documentos e testemunhos. É a partir deles que se entra em contato com os assuntos humanos. É do solo comum da verdade que construiremos e emitiremos opiniões, que buscaremos significados e estratégias para o enfrentamento de crises. Negar os fatos agrava a crise e condena as pessoas ao isolamento.

Entrar em contato com o "mundo", convertido na escola em "matérias" e "conteúdos", exige também a ação dos estudantes. Embora a "ação" seja um conceito (em $A$ Condição Humana, de Hannah Arendt) especialmente político, relativo às atividades dos adultos, considero que cabe à escola criar espaços de ação especificamente escolar ${ }^{14}$, pois à escola cabe introduzir os estudantes no "mundo" (ARENDT, 2007), e nos inserimos nele com a palavra e a ação (ARENDT, 2005, p. 206). Agir, para Arendt (2005), significa iniciar, começar, pôr em movimento, enfim, liberdade. A ação abre uma brecha nas expectativas (sociais, econômicas, políticas, familiares), esperando nela o inesperado, o improvável. A ação é a condição de possibilidade da política, e a política, da democracia. Não há democracia sem ação, sem a possibilidade do dissenso e do consenso.

A ação na escola, realizada pelos estudantes e professores, não é o mesmo que liberdade para se fazer o que se quer. Não se inscreve numa perspectiva sem limites. O limite é o "mundo" e a autoridade do professor, representante do mundo em relação às crianças e responsável pelo desenvolvimento, aprendizado e educação. Agir na sala de aula quer dizer atuar e responder às demandas, indagações, problematizações, "afrontas" do outro, os colegas e professores, e do "mundo", as "matérias". A democracia e a ação não são projetos, é preciso afirmá-las na existência, na prática, caso contrário a escola passa a ser um instrumento, e os estudantes, objetos das "políticas educacionais" e intervenções dos adultos. Para Gert Biesta (2013, p. 184),

\footnotetext{
as escolas que não mostram interesse pelo que os estudantes pensam ou sentem, onde não há espaço para os estudantes tomarem iniciativa, onde o currículo só é visto como matérias que precisam ser inseridas nas mentes e nos corpos dos estudantes, e onde nunca se leva em conta a questão do impacto dos inícios de uma pessoa sobre as oportunidades de os outros começarem, são claramente lugares onde é extremamente difícil agir e ser um sujeito democrático.
}

$\mathrm{Na}$ "Pós-Democracia", não se respeitam os limites, e a tendência escolar é transformar os estudantes em números ou objetos de uma idealização, não lhes dando a oportunidade de experimentar o mundo e a si mesmos como novidade. Evidentemente que essa tendência autoritária não se inicia com o contexto aqui estudado, mas se torna um agravante a mais nas possibilidades de ruptura, dado que limita o aparecimento do novo e das novas gerações como indivíduos singulares que nunca existiram antes e nem existirão depois de sua morte. Nesse sentido, na ação os indivíduos revelam quem são, descobrimento que está implícito nas palavras e ações. Na escola, não nos apropriamos de um conteúdo, habilidade ou competência. Respondemos ao mundo e, assim, aparecemos como singulares e, ao mesmo tempo, corrigimos nossos sentidos pessoais com os sentidos dos demais, criando um sentido de comunidade, de não estar só no mundo, mas compartilhando-o com outros iguais e distintos.

14 Argumentei sobre essa tese no artigo A ação educativa em Hannah Arendt (PETRY, 2019).

Educação em Revista|Belo Horizonte|v.37|e25258|2021 
Em relação aos limites, característica central da "pós-democracia", trata-se de superá-los, isto é, desenvolver-se, considerando que a infância é uma etapa de desenvolvimento e não um fim em si mesma. E o estudante deve ir além de si mesmo, ou seja, das expectativas familiares, sociais, política e econômicas, começando outra vez, iniciando, enfrentando os ditos que lhe constituíram e as dificuldades para se tornar adulto e descobrir-se a si mesmo, suas capacidades, a aparecer enquanto indivíduo singular. Superar limites significa, também, confrontar-se com aquilo que não sou eu, abrir-se ao outro, à alteridade, ao mundo, e respeitar os conhecimentos da criança não quer dizer ratificá-los, "mas saber em que nível de construção elas se encontram para, daí, levá-las a conhecimentos mais complexos e sólidos" (LA TAILLE, 2003, p. 26).

O outro elemento pertinente à "educação democrática" em contextos 'pós-democráticos" é o respeito aos limites. A verdade, como argumentado, é um limite à fantasia e à ideologia que tendem a destruir o mundo, isto é, a esfera de ação, o espaço público. Mas os limites não são contrários à ideia de liberdade, estão relacionados e só têm sentido quando se inter-relacionam. A liberdade, no sentido político e educacional, acontece apenas no entre, isto é, na relação que os indivíduos estabelecem entre si e, assim, aparecem como seres singulares. À suposta ou potencial ilimitação do indivíduo ou grupos, o preço pago é não aparecer como singular, como alguém que importa, mas apenas como funções. A ilimitação, do "tudo é possível", destrói os outros e a liberdade. Para Arendt (2007, p. 195), "sem um âmbito público politicamente assegurado, falta à liberdade o espaço concreto onde aparecer". Em termos educacionais, sem o escolar, isto é, o espaço/tempo do "tempo livre", falta à liberdade e à singularidade dos "novos" o espaço onde aparecer, pois a escola suspende a família, a economia, a política, as expectativas sociais. "O tempo escolar é o tempo tornado livre e não é tempo produtivo" (MASSCHELEIN; SIMONS, 2013, p. 33). Portanto, o escolar é um limite para a ilimitação do capital e da "racionalidade neoliberal", pois nem um (capital) nem outro (neoliberalismo) são possíveis sem a superação e destruição de limites, fronteiras, contenções.

Na sociedade "pós-democrática", não há "tempo livre" (skholê), liberdade das necessidades da "vida", da coação dos demais e da política (ARENDT, 2005, p. 40); tudo se transforma em "tempo produtivo", no qual as necessidades imperiosas da sobrevivência (trabalho, consumo, divertimento, entretenimento, negócios e sono) são as únicas e as dotadas de "sentido". Em tal contexto, não há democracia, apenas gestão da economia e dos indesejáveis.

Um "Outro mundo possível" não é construído por meio da educação. A escola não é um instrumento e se localiza fora das demandas sociais, políticas, econômicas ou familiares. Não é instrumento porque as crianças e jovens não são "objetos" e porque toda "novidade" apresentada pelos adultos às crianças seria velha. A essência da educação, segundo Arendt (2007, p. 223), é a "natalidade", o fato de que as crianças nascem no mundo. Não nascem para o trabalho (labor), para a família, para a política ou para a sociedade, mas para participar do mundo, assumir a responsabilidade por ele e aparecer como um indivíduo singular. $\mathrm{Na}$ "pós-democracia", a escola representa uma esperança no novo que cada geração aporta. Porém, "tudo destruímos se tentarmos controlar os novos de tal modo que nós, os velhos, possamos ditar sua aparência futura" (ARENDT, 2007, p. 243). A escola, quando escolar, é um limite para a "colonização" da existência pelo "tempo produtivo", oportunizando aos seres humanos ser introduzidos no mundo.

Esse sentido de limite, "limitar algo", ocorre quando na escola, do "tempo livre", os estudantes enfrentam as tarefas e os conteúdos ("mundo") e se dedicam a elas, sem as injunções do futuro ("o que devo ser?", "qual a utilidade disso?") e do passado ("sempre fui", "não conseguil", "meus pais acham que") no aqui, nisso, no "presente da encarnação", como escreve Pennac (2008, p. 59). Isso significa que "é necessário deixar de sacudir o passado como uma vergonha e o futuro como um castigo" (PENNAC, 2008, p. 59). Há, nessa reflexão, dois sentidos de limite: um "castrador" ou "assujeitador" e outro "emancipador". O primeiro, quando o passado e o futuro são como "cercas" que delimitam a passagem, os desafios e para onde se irá. No segundo, o limite é aos adultos (pais e professores), para não apresentar o passado como fracasso e o futuro como condenação. É emancipador no sentido de Rancière, segundo Masschelein e Simons (2014, p. 84), isto é, de "reivindicar o tempo que a burguesia requeria para si própria, o tempo livre ou morto, ou seja, um tempo não econômico". 
Esse limite estabelecido pelo escolar necessita de uma dimensão "técnica", ou seja, mobilizar os estudantes para a atenção ao mundo, a sua apresentação e criação. O método escolar, no sentido de skholé, deve ser conectado ao "mundo" dos jovens, mas com o objetivo de removê-los desse limite para que possam ir além, como argumentei acima. O "ir além" só é radical quando não está preso à lógica instrumental, na qual o futuro (resultado) orienta as ações e as avaliações. Por isso, as tarefas não estão voltadas a resolver problemas, a habilidade requerida pelo novo jargão da gestão empresarial, mas em ser confrontado com o "mundo" (o "outro") e consigo mesmo. $\mathrm{Na}$ escola, não há problemas, apenas questões, escrevem Masschelein e Simons (2013, p. 61). O "método" ou a "técnica" é meio, não fim. E nem todo "método" ou "técnica" pode ser utilizado em sala de aula nem é a garantia de uma relação educacional que introduza os alunos no "mundo" e permita o confronto e o encontro consigo mesmo e com os outros.

A confiança irrestrita num método é um equívoco que Arendt já atentava em $A$ crise na educação. Para a autora (2007, p. 231), reduzir a formação do professor a técnicas e métodos e não aos "conteúdos" abandona os estudantes aos seus próprios recursos e fragiliza a fonte de autoridade do adulto, fundada na "responsabilidade" em relação ao mundo e ao desenvolvimento dos estudantes. Novamente, o termo "conteúdo", "matéria", "conhecimento disciplinar", retorna ao argumento, e é fundamental destacar como a Base Nacional Comum Curricular (BNCC - Ensino Médio) destitui a educação de sua essência e contribui com a "pós-democracia" ao dar relevância ao desenvolvimento de habilidades e competências e, ao mesmo tempo, tornar os conteúdos secundários a esse "aprender a aprender" que resume a "linguagem da aprendizagem" (BIESTA, 2013). A democracia, aliás, como conceito, não aparece nenhuma vez no documento.

Se a formação para a cidadania é um dos eixos do documento relativo às Ciências Humanas Sociais e Aplicadas, seu fundamento é ético, no sentido do documento: "entendendo-se ética como um juízo de apreciação da conduta humana necessária para o viver em sociedade (BNCC, 2018, p. 547). Há uma opção intelectualista do aprendizado da ética e não de uma fundada em práticas ${ }^{15}$. Tal debate remonta à Antiguidade Grega, em especial, Platão e Aristóteles.

$\mathrm{Na}$ paideia platônica, registrada em $A$ República, a tese ético-formativa é a de que ninguém é mau voluntariamente, ou seja, o indivíduo sábio é bom (2019, \$350b). Platão não concebia que alguém, tendo acesso às verdades eternas, concebesse viver de modo contrário; alcançado o Bem, desejasse o mal. Educacionalmente, a implicação é que a educação moral, que é cidadã, acontece em conjunto com uma instrução filosófico-intelectual por meio da investigação sobre a essência do que é. "O diálogo e a arte de perguntar inauguram o processo metodológico ou dialético da educação, que tem como meta final alcançar a virtude ou a excelência da ação humana", argumenta Paniavi (2008, p. 49).

Aristóteles, por outro lado, critica seu mestre argumentando que para Sócrates "não existe aquilo que se chama de incontinência, pois ninguém, dizia ele, age contrariamente ao que considera melhor, consciente de estar agindo mal, a não ser por ignorância” (ARISTÓTELES, 1993, \$1146a). Há indivíduos que conhecendo o bem (o certo, o verdadeiro) atuam de modo contrário, conscientes, mas incapazes de resistir ao desejo. Deseja-se o bem, mas se atua de forma má. Nesse sentido, a BNCC se equivoca ao aspirar uma formação ética baseada num modo de educação exclusivo para as virtudes intelectuais e não para as virtudes morais que implicam uma educação pelas práticas que se convertem em hábitos: "tornamo-nos justos praticando atos justos, moderados agindo moderadamente, e corajosos agindo corajosamente" (ARISTÓTELES, 1992, \$1103B). Em nosso tema, uma educação democrática implica a prática de valores democráticos, e não apenas o esclarecimento intelectual dos conceitos ou a leitura de um manual. Nas palavras de Garcia e Puig (2007, p. 20-21),

não é possível que alguém adquira virtudes por meio das explicações que lhes são oferecidas pelos adultos, nem por meio da simples memorização dessas explicações. A aquisição desse saber exige exercício e a participação em práticas próprias de uma comunidade.

\footnotetext{
15 Os verbos utilizados são expressivos dessa opção "intelectualista”: analisar, identificar, discutir, elaborar hipóteses, identificar, criticar, utilizar, contrapor, comparar, compreender, problematizar, avaliar, contextualizar, caracterizar, relacionar, conhecer (BNCC, 2018, p. 559-565).
} 
Os saberes necessários ao exercício democrático envolvem, também, valores que se aprendem na prática, segundo distinção das virtudes por Aristóteles. A exposição e/ou estudo teórico não são compatíveis com o pleno desenvolvimento da democracia que não é simplesmente uma forma de governo, mas um modo de existir, o democrático. Sem dúvida que o esclarecimento conceitual, o estudo histórico, sociológico e filosófico da política é fundamental. Mas se o anseio é que o conhecimento repercuta na ação, ele deve ser convertido em práticas que se tornem hábitos pela constância, intencionalidade e periodicidade. Não se trata de determinar comportamentos, mas refletir e criar condições para a tomada de decisão em situações de conflito moral com base em "boas razões" (PUIG, 1998 , p. 21). Por outro lado, as ações, comportamentos e atitudes passadas, tudo o que nos acontece precisa ser objeto do pensar, da busca de sentido. É assim que o pensamento se articula com a ação, quando o indivíduo deixa temporariamente o "mundo" para prestar contas a si mesmo, na atividade de pensar, quando não sou mais um, mas dois, e ninguém gostaria de conviver com um criminoso, assassino, mentiroso, ressentido, vingativo, odiento ou imoral.

Portanto, o pensar tem um lugar privilegiado na educação escolar, na medida em que a escola se distancia do mundo (a escola não é o mundo), ao mesmo tempo em que suspende a família, o trabalho, a sociedade, a economia e a política. Na skholé da escola, se cultiva a imaginação, a reflexão, o pensar, o conhecer, enquanto se atua e se aparece como indivíduo singular e, portanto, se potencializa a democracia e a política.

\section{CONSIDERAÇÕES FINAIS}

O objetivo do presente estudo foi investigar qual o sentido da educação no contexto da "pós-democracia". Entendo que a educação não deve ser instrumental, ou seja, um meio para um fim externo a ela. A educação é a esperança que temos de que as "novas gerações" serão introduzidas no "mundo" e se tornarão responsáveis por ele, o que não significa que a "introdução" seja instrumental, mas acontece na "ação", pelas respostas que os estudantes dão às questões do mundo e ao aparecimento de outros indivíduos (colegas, professores, funcionários). A ação e o discurso têm como "solo" o conhecimento e a verdade. Ambos são limites para a fantasia (alucinose) que destrói o mundo e converte tudo em movimento (teorias da conspiração, pós-verdade, ideologia). Na educação, segundo Arendt (2007), aprendemos como o mundo é e não uma forma de viver. Quando vivemos, não existimos no singular, mas como membros de uma espécie. Despersonalizar, dessingularizar é a prática corrente de regimes tirânicos e totalitários que não estão interessados na ação e na existência do "outro". Nesse sentido, cabe indagar: qual o espaço que o "outro" têm para aparecer na escola (física e representativamente, nos livros didáticos, literários e obras de arte)?

A verdade, o conhecimento e o "outro" nos confrontam com nossas idealizações e/ou ilusões, e a escola é o espaço privilegiado do confronto, das questões que exigem resposta e reflexão pelos indivíduos. Por isso, o tema principal que ocupa a "educação democrática" em um contexto "pósdemocrático" são os limites, pois na "pós-democracia" não há o respeito aos limites dos poderes (econômicos, políticos e, porque não, individuais e familiares). Como a educação é uma exigência do "mundo", é razoável não confiar essa atividade às famílias ou organizações sociais privadas destinadas a oferecer um serviço para o consumo privado. Ao sair de casa, temos a oportunidade de descobrir o "mundo" e, ao mesmo tempo, a nós mesmos como únicos, rompendo com os juízos paternos e maternos e a oportunidade de começar outra vez, o milagre da ação. A escola é um limite ao domínio familiar para que a criança deixe de desejar o desejo da mãe e se torne desejante de seus desejos ao mesmo tempo em que é educada nos limites, porque há um "mundo" que não é ela e não gira ao seu redor e uma realidade que se constitui pela "ação" e é construída pela "fabricação" dos homens e mulheres, dependendo da correção dos sentidos ("senso comum") que acontece no encontro.

O escolar impõe limites também ao "tempo produtivo", típico da Modernidade e radicalizado com a "racionalidade neoliberal", na qual as pessoas são instadas a se ver e se conceber como empresárias de si. Neoliberalismo e "pós-democracia" estão articulados, porque o primeiro é a fragilização dos limites ao poder econômico ao mesmo tempo em que se amplia a violência do Estado 
no gerenciamento dos indesejáveis. $\mathrm{Na}$ escola, não há indesejáveis nem os estudantes são empresários de si. Não são "capital humano" a ser desenvolvido e rentabilizado, mas seres humanos que descobrem ao mundo e a si mesmos. Assim, a escola escolar se localiza no aqui, no agora e estuda isso, o "tempo presente": o limite ao passado e ao futuro, um lapso no tempo para "perder-se no tempo" e encontrar o "outro" em sua outreidade e se descentrar, sair de si e constituir um sentido para o que acontece.

A educação no contexto da "pós-democracia" não é uma educação para a democracia, como se fosse um projeto, uma promessa futura. A educação é democrática, das práticas de valores democráticos que se convertem em hábitos, da experiência escolar da igualdade, não de apropriação de um bem presente (conhecimento) ou futuro (ascensão social), mas de "ser capaz de" como ponto de partida. A igualdade não é um projeto, mas uma hipótese que principia toda ação pedagógica. A escola é uma esperança para o mundo e, ao mesmo tempo, para as novas gerações, porque independentemente do que se passou ou das promessas trágicas ou triunfais de um futuro incerto, cada aluno tem a capacidade de se interessar por alguma coisa e se desenvolver de maneira significativa e aparecer como único, a despeito das expectativas conformistas da sociedade.

\section{REFERÊNCIAS}

AB'SÁBER, Tales. Crise, alucinose e mentira: o anticomunismo do nada brasileiro. In.: ALMEIDA, Ronaldo. TONIOL, Rodrigo. Conservadorismos, fascismos e fundamentalismos: análises conjunturais. Campinas/SP: Editora Unicamp, 2018. p.117-142.

ARENDT, Hannah. A dignidade da política: ensaios e conferências. Rio de Janeiro: Relume-Dumará, 1993.

ARENDT, Hannah. A vida do espírito: o pensar, o querer, o julgar. Rio de Janeiro: Civilização Brasileira, 2009.

ARENDT, Hannah. Crises da República. São Paulo: Perspectiva, 2006.

ARENDT, Hannah. Eichmann em Jerusalém: um relato sobre a banalidade do mal. São Paulo: Cia das Letras, 2013.

ARENDT, Hannah. Entre o passado e o futuro. 6.ed. São Paulo: Perspectiva, 2007.

ARENDT, Hannah. Homens em tempos sombrios. Lisboa: Relógio D’Água, 1991.

ARENDT, Hannah. La condición humana. Barcelona: Paidós, 2005.

ARENDT, Hannah. Origens do totalitarismo: antissemitismo, imperialismo, totalitarismo. São Paulo: Cia das Letras, 2012.

ARISTÓTELES. Ética a Nicômacos. 3.ed. Brasília: Universidade de Brasilia, 1992.

BRASIL. Constituição da República Federativa do Brasil. 55.ed. São Paulo: Saraiva Educação, 2018.

BERNSTEIN, Richard. ¿Cambió Hannah Arendt de opinión? Del mal radical a la banalidad del mal. In: BIRULÉS, Fina. Hannah Arendt: el orgullo de pensar. Barcelona: Gedisa Editorial, 2006. p. 235-257.

BIESTA, Gert. Para além da aprendizagem: educação democrática para um futuro humano. Belo Horizonte: Autêntica, 2013. 
CASARA, Rubens. Estado Pós-Democrático: neo-obscurantismo e gestão dos indesejáveis. Rio de Janeiro: Civilização Brasileira, 2018a.

CASARA, Rubens. Sociedade sem lei: pós-democracia, personalidade autoritária, idiotização e barbárie. Rio de Janeiro: Civilização Brasileira: 2018b.

ESTEFANÍA, Joaquín. La mentira os hará más eficaces. In: FANÉS, Jordi Ibañez (ed.) En la era de la posverdad. 14 ensayos. Barcelona: Calambur, 2017. p.79-89.

FRATESCHI, Yara. Antibolivarianismo à brasileira. In: ALMEIDA, Ronaldo. TONIOL, Rodrigo. Conservadorismos, fascismos e fundamentalismos: análises conjunturais. Campinas/SP: Editora Unicamp, 2018. p.117-142.

GARCÍA, Xus Martin; PUIG, Josep María. As sete competências básicas para educar em valores. São Paulo: Summus, 2010.

KERSHAW, Ian. Hitler. São Paulo: Cia das Letras, 2010.

HESSE, Herman. Demian. 22.ed. São Paulo: Record, 2000.

LA TAILLE, Yves. Limites: três dimensões educacionais. São Paulo: Ática, 2003.

LEBRUN, Jean-Pierre. Um mundo sem limites. Rio de Janeiro: Cia de Freud, 2004.

MASSCHELEIN, Jan. SIMONS, Maarten. A pedagogia, a democracia, a escola. Belo Horizonte: Autêntica, 2014.

MASSCHELEIN, Jan. SIMONS, Maarten. Em defesa da escola: uma questão pública. Belo Horizonte: Autêntica, 2013.

MCEWAN, Ian. A barata. São Paulo: Cia das Letras, 2020.

MINISTÉRIO DA JUSTIÇA. Projeto de Lei Anticrime. Anteprojeto de Lei. Disponível em: https://www.justica.gov.br/news/collective-nitf-content-1549284631.06/projeto-de-lei-anticrime.pdf. Acesso em 23 de mar. de 2020.

MONEDERO, Juan Carlos. ¿Posdemocracia? Frente al pesimismo de la nostalgia, el optimismo de la desobediencia. Nueva Sociedad. n. 240, p.68-86, jul./ago. 2012.

PAVIANI, Jayme. Platão \& a Educação. Belo Horizonte: Autêntica, 2008.

PELED-ELHANAN, Nurit. Ideologia e propaganda na educação: a Palestina nos livros didáticos israelenses. São Paulo: Boitempo; Editora Unifesp, 2019.

PENNAC, Daniel. Mal de escuela. Barcelona: Penguin Random House, 2008.

PETRY, Cleriston. A 'ação educativa' em Hannah Arendt. Conjectura: Filosofia \& Educação. Caxias do Sul: UCS, vol. 04, p.1-21, 2019.

PLATÃO. A República. 3.ed. São Paulo: Edipro, 2019. 
PUIG, Josep María. Ética e valores: métodos para um ensino transversal. São Paulo: Casa do Psicólogo, 1998.

SANZ, Marta. La mala calidad: educación, verdad, expresión, democracia. In.: FANÉS, Jordi Ibañez (ed.) En la era de la posverdad. 14 ensayos. Barcelona: Calambur, 2017. p.49-63.

SAVATER, Fernando. El valor de educar. 6.ed. Barcelona: Editora Planeta, 2011.

TAPIAS, José Antonio Pérez. Claves humanistas para una educación democrática: de los valores humanos al hombre como valor. Madrid: Anaya, 1996. 